\title{
Avaliação de Parâmetros de Qualidade de Águas Superficiais em Mananciais do Município de Jales - SP
}

\section{Evaluation of Quality Parameters of Superficial Water in Springs from Jales - SP}

PRANDI-ROSA, G. A. ${ }^{1}$, FARACHE FILHO, A. ${ }^{2}$

${ }^{1}$ Centro de Estudos Ambientais-CEA/UNESP - Pós-Graduação

${ }^{2}$ Faculdade de Ciências Farmacêuticas - Araraquara -UNESP

\section{RESUMO}

Avaliaram-se parâmetros de qualidade de águas superficiais em mananciais do Município de Jales, SP, considerando-se sua importância, não somente como um recurso natural vital, mas também relacionada à sua quantidade, qualidade e disponibilidade para uso pela comunidade e interação com os fatores ambientais associados à bacia hidrográfica. A escolha da área baseou-se no fato de constituir em uma das sub-bacias do Rio São José dos Dourados e não apresentar nenhum tipo de estudo ou análise ambiental para fins acadêmicos. Foram avaliados os seguintes parâmetros: demanda química de oxigênio, demanda bioquímica de oxigênio, turbidez, coliformes totais e E. coli. Durante 12 meses, amostras foram colhidas mensalmente em sete estações dos Córregos do Marimbondinho e do Tamboril e do Ribeirão Marimbondo, e, trimestralmente, em duas estações no efluente do Frigorífico. Este estudo teve como objetivo avaliar a intensidade das alterações provocadas pelas descargas de esgotos domésticos e efluente do Frigorífico nas águas dos corpos receptores e verificar a eficiência do tratamento do efluente industrial deste frigorífico e sua influência nos níveis de poluição dos córregos e ribeirão estudados, mensurando os indicadores (parâmetros) de poluição citados anteriormente; visa ainda fornecer subsídios para o planejamento regional integrado e conservação da sub-bacia e, conseqüentemente, da bacia hidrográfica do Rio São José dos Dourados. Concluiu-se que os lançamentos de esgotos domésticos e dos resíduos líquidos industriais do Frigorífico elevam sensivelmente os níveis de poluição das águas dos corpos receptores quanto aos parâmetros estudados; além disto, o tratamento efetuado no efluente do Frigorífico não é suficiente para reduzir a carga 
poluidora aos níveis recomendados para que seja despejado nos córregos.

Palavras-chave: Qualidade da água, demanda química de oxigênio, demanda bioquímica de oxigênio, turbidez, coliformes, Escherichia coli.

\section{ABSTRACT}

It was evaluated Quality Parameters of Superficial Water in Springs in Jales - SP, its importance, not only as a vital natural resource but also as a quantity, quality and by its availability to be used by the community and its interaction with environmental factors associated to the hydrographic basin. The area was chosen based on the fact that it's constitutes at one of the sub-basins of São José dos Dourados River and doesn't have any kind of studies or environmental analysis for academic aims. It was evaluated the following parameters: oxygen chemical demand, oxygen biochemical demand, turbid, total coliforms and E. Coli. For 12 months, samples were collected monthly from seven stations of Marimbondinho and Tamboril Streams and also of Marimbondo River and trimestrally from two stations at the effluent of the Frigorifico (cold store) in the water of the receiver bodies and check the treatment efficiency of industrial effluents (of this cold store) and also its influence on the pollution levels in the streams and rivers which were studied; measuring the pollution indicators (parameters) previously mentioned and also supply the integrated regional planning and the sub-basin preservation with subsidies and consequently the hydrographic basin of São José dos Dourados River. We concluded that throuing domestic sewer and industrial liquid residues of the cold store increases sensitively the pollution levels of the water of receiver bodies as for the parameters studied; after all, the treatment made on the effluent of the cold store isn't enough to reduce the pollutant charge to recommended levels to be thrown into the streams.

Key-words: Water quality, oxygen chemical demand, oxygen biochemical demand, turbidity, coliforms, Escherichia coli.

\section{INTRODUÇÃO}

Ao analisar a problemática ambiental considera-se que a avaliação ambiental é a mais ampla atividade analítica. Avaliar o ambiente significa compreendê-lo e mensurá-lo, segundo relações entre seus elementos e aspectos físicos, biológicos, econômicos, sociais e culturais (MACEDO, 1991).

Parece bastante evidente, para boa parte da humanidade, que a questão ambiental não pode mais ficar fora das muitas preocupações do homem moderno. Talvez seja este um dos poucos consensos mínimos alcançados. Os problemas ambientais precisam ocupar um papel de destaque na agenda das diferentes nações neste final de 
século (BARCELOS, 1997). A necessidade da melhoria da qualidade de vida através da manutenção do equilíbrio ambiental constitui questão indiscutível (PEÇANHA, 1993).

A questão ambiental apresenta-se hoje como uma das principais bandeiras políticas, tanto em países desenvolvidos como em desenvolvimento, mas ainda se denotam inúmeras dificuldades a serem sanadas para que se efetivem avanços nesse setor.

Apesar da água ser considerada um recurso abundante, relativamente aos usos e demandas atuais, existem áreas muito carentes a ponto de transformá-la em um bem limitado às necessidades do homem. Normalmente, a sua escassez é muito mais grave em regiões onde o desenvolvimento se processou de forma desordenada, provocando a deterioração das águas disponíveis pelo lançamento indiscriminado de esgotos domésticos, despejos industriais, agrotóxicos e outros poluentes (MOITTA \& CUDO, 1991).

Da reserva mundial de água, 97,2\% é constituída pela água dos oceanos e mares e $2,15 \%$ pela água contida nos "glaciers" e "icebergs" polares. Os $0,63 \%$ restantes, que estão distribuídos entre a terra e a atmosfera, representam oito milhões e quinhentos mil $\mathrm{Km}^{3}$ de água ( constituem o volume de todos os rios e lagos do mundo, de toda a água subterrânea, da umidade contida no solo e do vapor d'água presente na atmosfera). Desses oito milhões e quinhentos mil $\mathrm{Km}^{3}$, dos quais cerca de $48 \%$ são águas subterrâneas até oitocentos metros de profundidade, $49 \%$ abaixo de oitocentos metros de profundidade, $1,5 \%$ estão nos rios, lagos e cursos d'água, $0,8 \%$ na umidade do solo e 0,7\% no vapor d'água na atmosfera (MOITTA \& CUDO, 1991).

Na verdade, a crise não é de recursos hídricos, mas de sua utilização. No caso latino-americano, o aumento da demanda decorreu da mudança do modelo econômico na região. Temos uma disponibilidade no Brasil de $35 \mathrm{mil} \mathrm{m}^{3}$ per capita. Isto significa quase 17 vezes o que tem a Alemanha e quase 10 vezes a França. Portanto, temos muita água. E talvez, por isso mesmo, nos damos o direito de deteriorá-la, gastando-a de forma extremamente irresponsável. Por falta de boa administração o país já enfrenta crise de abastecimento em algumas áreas como é o caso das cidades de São Paulo e Rio de Janeiro e do semi-árido nordestino. Falta gerenciamento, pois, se houvesse, São Paulo com $9.000 \mathrm{~m}^{3}$ per capita não teria por que se preocupar. A Alemanha tem apenas $1.500 \mathrm{~m}^{3}$ e vive muito bem. A cidade de São Paulo está em processo de degradação acelerado, pois, segundo a Companhia de Tecnologia de Saneamento Ambiental (CETESB), a cada dois anos dobra a extensão dos rios com águas tão degradadas que não se pode fazer um tratamento convencional. A fiscalização ambiental implantado no Brasil levou a um controle relativamente eficiente dos despejos industriais, porém o vilão é o governo já que as empresas públicas de saneamento não 
tratam as água residuárias de forma correta (REBOUÇAS, 1995).

O Brasil, embora possa considerar-se privilegiado em relação a outros países, convive com problemas. A bacia amazônica concentra $70 \%$ da água superficial do país, para atender a $7 \%$ da população. Os restantes $93 \%$ de brasileiros compartilham $30 \%$ da água. Na Região Sudeste, onde moram $42 \%$ dos brasileiros, estão localizados $6 \%$ da água (MOURA, 1997). Em reservas de água potável, o Brasil não tem do que se queixar, diante da distribuição das fontes de água doce em metros cúbicos por pessoa, se comparado com alguns países, além de possuir cerca de $11,6 \%$ de toda a água doce superficial do mundo.

Esse é o paradoxo da água: rara em muitos lugares povoados onde a população morre de sede por sua falta, abundante em várias regiões desertas e poluídas em outras, a ponto de destruir a flora e a fauna (MOITTA \& CUDO, 1991).

Atualmente, percebe-se uma nova tomada de consciência referente aos recursos hídricos, que nem sempre teve o papel de importância e de destaque que lhe são atribuídos hoje. A água não é só um recurso vital e escasso, mas também, tanto pela quantidade como pela qualidade, um condicionante do desenvolvimento econômico e do bem estar social. A água foi por muito tempo vista como um bem inesgotável e quase gratuito, sendo bastante recente a mudança de mentalidade de que ela é um recurso progressivamente escasso e de custo mais elevado, exigindo, por isso mesmo, planejamento e manejo adequados (AZPURUA \& GABALDON, 1976).

\section{JUSTIFICATIVA}

Embora os problemas mais graves de poluição ocorram nas grandes metrópoles, não se pode desprezar os impactos causados em centros urbanos de pequeno e médio porte. Dos 655 municípios do Estado de São Paulo, a maioria tem populações entre 1.600 e 45.000 habitantes, concentradas principalmente na zona urbana, localizadas em diferentes áreas de uma mesma bacia hidrográfica. Muitos municípios captam águas superficiais, principalmente de rios, para abastecimento e a maioria lança os esgotos à jusante da captação. Deste modo, vários trechos de águas poluídas ocorrem em todas as regiões do Estado.

O crescimento das cidades e o aumento do recebimento dos resíduos líquidos industriais nas redes públicas têm ampliado a extensão dos trechos de rios poluídos, comprometendo a qualidade das águas para abastecimentos públicos, fins industriais, recreativos ou práticas desportivas, causando danos aos peixes e à indústria da pesca, prejuízos às propriedades marginais, à agricultura e pecuária, à fauna natural que inclui as aves migrantes e animais selvagens, à regularização das águas para finalidades múltiplas ou específicas e à drenagem, enfim, dificultando inclusive a autodepuração dos cursos de 
água (PHILIPPI JÚNIOR, 1992).

A questão do planejamento, tendo como unidade real uma bacia hidrográfica, implica em questões de natureza político-administrativa e econômica. É necessário que, previamente ao planejamento, se conheça o espaço a ser planejado (a bacia) como um organismo multifacetado, porém íntegro, no sentido de formar uma totalidade organizacional. Assim, pensar em planejar a cidade de Jales, por exemplo, sem levar em conta o Ribeirão Marimbondo ou os Córregos Marimbondinho e Tamboril é inócuo do ponto de vista da integração da bacia.

Os esgotos do município de Jales são provenientes de efluentes das atividades domésticas de residências, comerciais e da área institucional (semelhantes aos esgotos domésticos, porém gerados em escolas, hospital, prisão, repartições públicas) sem qualquer tratamento prévio; são lançados, através de dois emissários, no Córrego do Tamboril e no Córrego do Marimbondinho que formam o Ribeirão Marimbondo. Além desses, existe outro emissário que lança, no Córrego Marimbondinho, resíduos líquidos industriais tratados provenientes de um frigorífico.

O presente estudo justifica-se pela necessidade de maior atenção para a preservação e recuperação da qualidade das águas superficiais no município de Jales-SP, como problemas de saúde pública e ambiental graves, bem como pelo seu interesse acadêmico por se tratar de pesquisa pioneira na região, cujos resultados poderão oferecer subsídios para posterior avaliação dos reflexos da implantação e operação da estação de tratamento de esgotos na recuperação e melhoria da qualidade das águas dos Córregos Marimbondinho e Tamboril e Ribeirão Marimbondo.

\section{OBJETIVOS}

1. Avaliar a intensidade das alterações provocadas pelas descargas de esgotos domésticos nos Córregos do Marimbondinho e do Tamboril e Ribeirão Marimbondo e verificar a eficiência do tratamento do efluente industrial do Frigorífico Jales e sua influência nos níveis de poluição do Córrego do Marimbondinho e Ribeirão Marimbondo por meio dos seguintes parâmetros: demanda química de oxigênio, demanda bioquímica de oxigênio, turbidez, coliformes totais e Escherichia coli.

2. Determinar a influência do lançamento dos esgotos domésticos e industriais pelos indicadores de contaminação por bactérias coliformes, totais e E. coli, na sub-bacia dos Córregos Tamboril e Marimbondinho e Ribeirão Marimbondo;

3. Fornecer subsídios para o planejamento regional integrado e conservação dos Córregos Marimbondinho e Tamboril, Ribeirão Marimbondo e, conseqüentemente, da bacia hidrográfica do Rio São José dos Dourados. 


\section{MATERIAL E MÉTODOS}

\section{Área geográfica de estudo}

A bacia hidrográfica do Rio São José dos Dourados abrange uma área de drenagem de $6.142 \mathrm{Km}^{2}$ e uma população total de 207.716 habitantes. É composta principalmente pelo Rio São José dos Dourados que, nasce em Mirassol (SP), percorre 290 Km e deságua no Rio Paraná. A principal cidade desta bacia é Jales (SP) com uma população total de 43.793 habitantes (INSTITUTO BRASILEIRO DE GEOGRAFIA E ESTATÍSTICA, 1996).

Um dos afluentes da margem direita do Rio São José dos Dourados é o Ribeirão Marimbondo, formado pelo Córrego do Marimbondinho e o Córrego do Tamboril, com extensão de $30 \mathrm{Km}$, integrando o território dos municípios de Jales, Pontalinda e Dirce Reis, com uma população total de 48.736 habitantes (INSTITUTO BRASILEIRO DE GEOGRAFIA E ESTATÍSTICA, 1996), tendo as seguintes coordenadas geográficas: $20^{\circ} 16^{\prime}$ de latitude sul e $50^{\circ} 33^{\prime}$ de longitude a oeste de Greenwich. O clima é tropical com duas estações bem definidas, uma chuvosa e a outra seca, com as temperaturas mínimas elevadas mesmo nos meses mais frios (de maio a agosto), com médias sempre maiores que $12,5^{\circ} \mathrm{C}$; as temperaturas máximas raramente atingem $33^{\circ} \mathrm{C}$ de média mensal.

\section{Período do estudo e colheita de amostras}

As estações de colheita para amostragem da água foram determinadas considerando as funções do curso d'água, principalmente à montante e à jusante do lançamento de esgotos do município de Jales e do Frigorífico. Foram definidas nove estações de colheita, sendo quatro no Córrego do Marimbondinho, duas no Córrego do Tamboril, duas no efluente do Frigorífico (antes e após tratamento das águas residuárias) e uma no Ribeirão Marimbondo após receber as águas dos dois córregos. As amostras dos córregos e do ribeirão foram colhidas mensalmente e as do efluente do Frigorífico trimestralmente, num período de doze meses entre agosto de 1998 e julho de 1999.

A seguir, encontram-se relacionadas as estações de colheita (Figura 1).

Estação 1: Córrego do Marimbondinho, antes do lançamento do esgoto do Frigorífico.

Estação 2: Córrego do Marimbondinho, após emissão do esgoto do Frigorífico.

Estação 3: Efluente do Frigorífico Jales, antes do tratamento das águas residuárias. 
Estação 4: Efluente do Frigorífico Jales, após tratamento das águas residuárias.

Estação 5: Córrego do Marimbondinho, antes do lançamento do esgoto doméstico.

Estação 6: Córrego do Marimbondinho, após lançamento do esgoto doméstico.

Estação 7: Córrego do Tamboril, antes do lançamento do esgoto doméstico.

Estação 8: Córrego do Tamboril, após lançamento do esgoto doméstico.

Estação 9: Ribeirão Marimbondo, após confluência entre os Córregos do Marimbondinho e do Tamboril. 


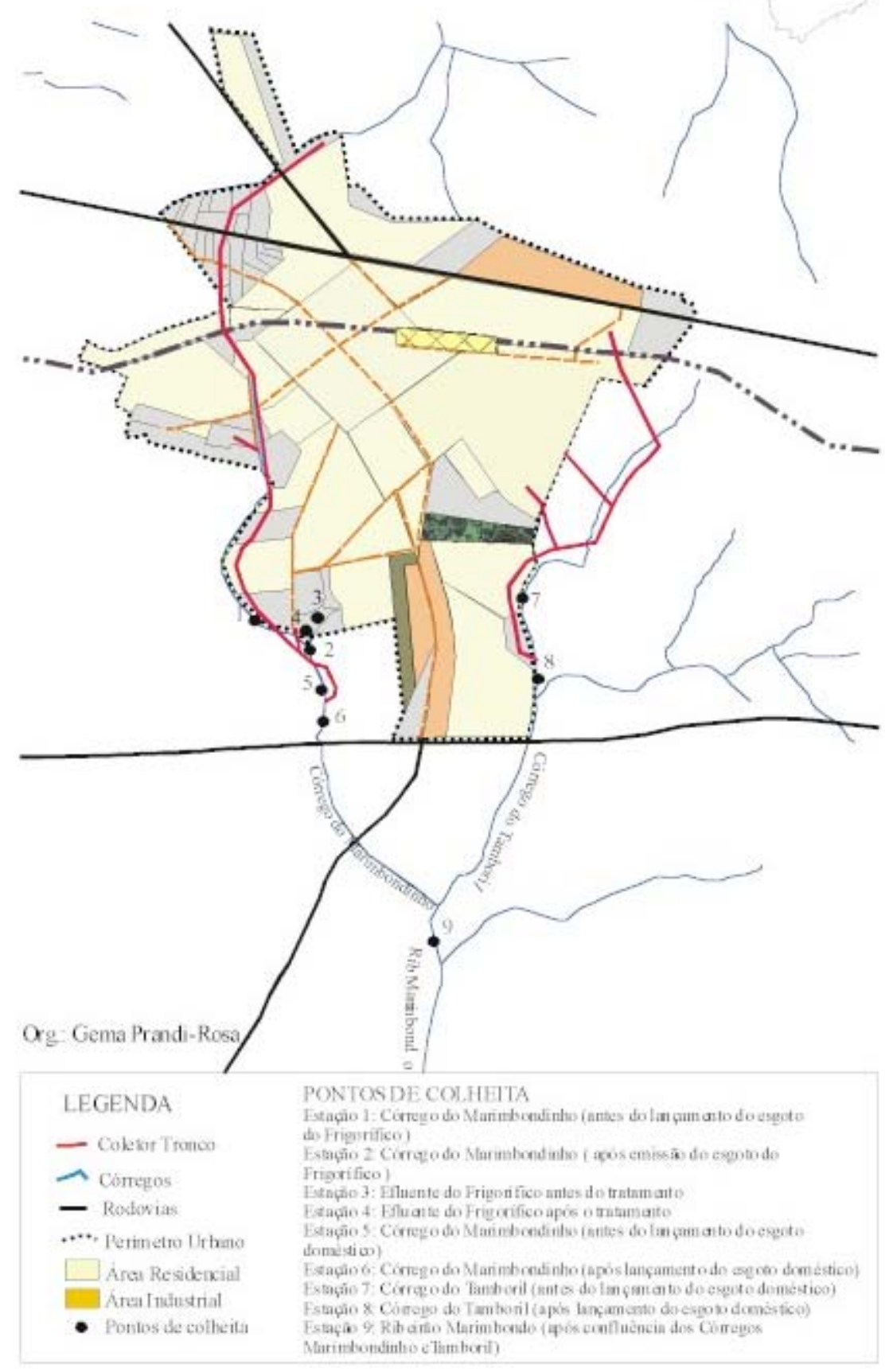

Figura 1. Mapa da zona urbana de Jales e estações de colheita.

Fonte: Prefeitura Municipal de Jales D. V. O. P. 1980.

\section{Parâmetros estudados}

Os parâmetros físico-químicos, físicos, químicos e biológicos escolhidos, podem dar uma idéia inicial sobre os compartimentos espaciais dos córregos e ribeirão e seu comportamento sazonal, que podem ser inferidos a partir dos valores obtidos para cada coleta. 
Foram realizadas análises e medições da demanda química de oxigênio, demanda bioquímica de oxigênio, turbidez, coliformes totais e Escherichia coli.

\section{Parâmetros físico-químicos, químicos e físicos}

\section{Demanda Química de Oxigênio}

Para a Demanda Química de Oxigênio foi utilizado o Sistema Hach, método de microdigestão em reator (banho seco com temperatura ajustável, controlado por um cronômetro que se desliga automaticamente), com refluxo fechado (tubo), seguido de leitura usando-se um espectrofotômetro (APHA, 1995).

\section{Turbidez}

Para determinação da turbidez utilizou-se um aparelho turbidímetro da marca Micronal modelo B.320, com escalas de 0 a 1000 UNT (Unidade Nefelométrica de Turbidez) devidamente calibrado. Agitou-se a amostra, colocou-se $30 \mathrm{~mL}$ em cubeta apropriada e inseriu-se no orifício do aparelho, cobrindo com o cone de proteção; fez-se a leitura imediatamente na escala indicada. (CETESB, 1978).

\section{Parâmetros biológicos}

Coliformes totais e Escherichia coli.

Para determinação da presença de bactérias coliformes totais e E. coli empregou-se a Técnica de Substratos Definidos (TSD) utilizando o produto da marca comercial Colilert fabricado pela empresa IDEXX (Innovators in Diagnostics). Este método está baseado na tecnologia enzimática por substratos definidos, onde são empregados nutrientes indicadores que fazem com que os microrganismos de interesse presentes na amostra produzam mudança de cor ao serem inoculados no sistema TSD e incubados na temperatura adequada (APHA, 1995).

\section{Demanda Bioquímica de Oxigênio}

A Demanda Bioquímica de Oxigênio (DBO) foi obtida partindo-se da diferença inicial e final do oxigênio dissolvido determinado na amostra após um período de cinco dias de incubação $\mathrm{DBO}_{5}$ (APHA, 1995). 


\section{RESULTADOS E DISCUSSÃO}

A DQO mede o teor de matéria orgânica em águas naturais, esgotos domésticos e resíduos líquidos industriais; sua determinação é simples e rápida, podendo ser empregada em casos onde a DBO não pode ser determinada de maneira precisa (BRAILE \& CAVALCANTE, 1979 apud BORGES, 2001).

A DQO expressa a quantidade de oxigênio necessária para a oxidação da matéria orgânica e inorgânica em amostras de água (ADAMS, 1990 apud BORGES, 2001) sem a intervenção de microrganismos (NOUR, 1994 apud BORGES, 2001). Segundo PALMA-SILVA (1999) a DQO determina a concentração de matéria orgânica presente na água sem indicar sua natureza ou diferenciar a constituição química das moléculas oxidáveis.

Verificou-se que houve aumento da DQO nos Córregos Marimbondinho e Tamboril como conseqüência do lançamento de esgotos domésticos e do efluente do Frigorífico, embora este último passe por processo de tratamento que reduz sensivelmente a DQO (Tabela 1).

Tabela 1. DQO em amostras de água nas nove estações de colheita nos Córregos do Marimbondinho e do Tamboril, efluentes do Frigorífico, e Ribeirão Marimbondo de agosto de 1998 a julho de 1999; Jales-SP.

\begin{tabular}{|c|c|c|c|c|c|c|c|c|c|}
\hline \multirow{2}{*}{$\begin{array}{l}\text { Data da } \\
\text { colheita }\end{array}$} & \multicolumn{9}{|c|}{ Estações de colheita } \\
\hline & E1 & E2 & E3 & E4 & E5 & E6 & E7 & E8 & E9 \\
\hline $25 / 08 / 98$ & 19,0 & 81,0 & & & 31,0 & 565,0 & 7,0 & 558,0 & 62,0 \\
\hline $22 / 09 / 98$ & 48,0 & 56,0 & & & 71,0 & 666,0 & 45,0 & 278,0 & 94,0 \\
\hline $27 / 10 / 98$ & 27,0 & 88,0 & 8103,0 & 335,0 & 55,0 & 594,0 & 22,0 & 128,0 & 115,0 \\
\hline $30 / 11 / 98$ & 7,0 & 55,0 & & & 42,0 & 600,0 & 12,0 & 260,0 & 42,0 \\
\hline $16 / 12 / 98$ & 7,0 & 139,0 & & & 75,0 & 448,0 & 12,0 & 684,0 & 111,0 \\
\hline $19 / 01 / 99$ & 36,0 & 53,0 & 3250,0 & 246,0 & 50,0 & 490,0 & 26,0 & 198,0 & 120,0 \\
\hline $25 / 02 / 99$ & 20,0 & 97,0 & & & 92,0 & 397,0 & 8,0 & 479,0 & 97,0 \\
\hline $18 / 03 / 99$ & 7,0 & 32,0 & & & 32,0 & 948,0 & 4,0 & 430,0 & 103,0 \\
\hline
\end{tabular}




\begin{tabular}{||r||r||r||r||r||r||r||r||r||r||}
$26 / 04 / 99$ & 13,0 & 104,0 & 4550,0 & 354,0 & 91,0 & 1069,0 & 17,0 & 481,0 & 72,0 \\
\hline $24 / 05 / 99$ & 10,8 & 10,9 & & & 32,4 & 368,0 & 49,4 & 685,0 & 120,0 \\
\hline \hline $21 / 06 / 99$ & 18,4 & 44,5 & & & 38,5 & 604,0 & 30,0 & 373,0 & 71,0 \\
\hline \hline $29 / 07 / 99$ & 6,0 & 64,0 & 2620,0 & 375,0 & 97,0 & 762,0 & 6,0 & 835,0 & 171,0 \\
\hline
\end{tabular}

A DBO é considerada um importante parâmetro para o controle da poluição das águas por matéria orgânica degradável. Em águas naturais representa a demanda potencial de oxigênio dissolvido que poderá ocorrer devido à estabilização dos compostos orgânicos biodegradáveis que, por sua vez, poderá reduzir os níveis de oxigênio nas águas abaixo do exigido (SABESP, 1997).

Não há nenhuma recomendação específica para $\mathrm{DBO}_{5}$, mas águas com níveis inferiores a 4,0mg. $\mathrm{L}^{-1}$ são consideradas razoavelmente limpas e com níveis superiores a $10,0 \mathrm{mg} . \mathrm{L}^{-1}$ são consideradas poluídas por conterem grandes quantidades de matéria orgânica degradáveis. Os maiores aumentos em termos de $\mathrm{DBO}_{5}$ nos corpos de água são provocados por despejos predominantemente compostos por matéria orgânica, cuja presença em teores elevados pode extinguir o oxigênio da água provocando a morte de peixes e outras formas de vida aquática (CETESB, 1995 apud PALMA-SILVA, 1999).

Verificou-se que ocorreu elevação dos níveis de $\mathrm{DBO}_{5}$ nas águas dos córregos após lançamento das águas residuárias provenientes de esgotos domésticos e do efluente do Frigorífico. Embora o tratamento do efluente do Frigorífico reduza bastante a $\mathrm{DBO}_{5}$, não poderia ser lançado no córrego, pois seus valores estão acima do permitido (60,0mg/L) pela legislação do Estado de São Paulo (Tabela 2).

Tabela 2. DBO em amostras de água nas nove estações de colheita nos Córregos do Marimbondinho e do Tamboril, efluentes de um Frigorífico e Ribeirão Marimbondo de agosto de 1998 a julho de 1999; Jales-SP.

\begin{tabular}{|c|c|c|c|c|c|c|c|c|c|}
\hline \multirow{2}{*}{$\begin{array}{l}\text { Data da } \\
\text { colheita }\end{array}$} & \multicolumn{9}{|c|}{ Estações de colheita } \\
\hline & E1 & E2 & E3 & E4 & E5 & E6 & E7 & E8 & E9 \\
\hline
\end{tabular}




\begin{tabular}{|c|c|c|c|c|c|c|c|c|c|}
\hline $25 / 08 / 98$ & 9,0 & 30,0 & & & 16,0 & 331,0 & 3,2 & 181,0 & 15,0 \\
\hline $22 / 09 / 98$ & 6,0 & 33,0 & & & 35,0 & 331,0 & 11,0 & 142,0 & 28,0 \\
\hline 27/10/98 & 6,5 & 25,5 & 3930,0 & 73,0 & 28,0 & 192,0 & 4,6 & 46,0 & 37,0 \\
\hline $30 / 11 / 98$ & 3,4 & 35,0 & & & 30,2 & 336,0 & 3,4 & 164,0 & 22,0 \\
\hline $16 / 12 / 98$ & 1,1 & 54,0 & & & 57,0 & 210,0 & 4,0 & 282,0 & 50,0 \\
\hline 19/01/99 & 12,6 & 40,0 & 1731,0 & 132,0 & 27,5 & 232,0 & 11,0 & 111,0 & 107,0 \\
\hline $25 / 02 / 99$ & 7,0 & 10,0 & & & 7,6 & 94,0 & 6,3 & 90,8 & 270 \\
\hline $18 / 03 / 99$ & 2,0 & 31,4 & & & 28,9 & 502,8 & 1,8 & 236,0 & 53,2 \\
\hline $26 / 04 / 99$ & 3,7 & 33,0 & 2811,0 & 93,9 & 77,0 & 385,2 & 7,1 & 261,0 & 61,0 \\
\hline $24 / 05 / 99$ & 4,5 & 4,7 & & & 12,0 & 98,5 & 15,8 & 166,7 & 33,7 \\
\hline 21/06/99 & 6,2 & 21,3 & & & 16,7 & 272,1 & 11,3 & 144,2 & 40,0 \\
\hline $29 / 07 / 99$ & 1,0 & 28,1 & 1200,0 & 79,5 & 30,8 & 445,3 & 0,6 & 358,3 & 66,7 \\
\hline
\end{tabular}

A turbidez da água é a medida de sua capacidade em dispersar a radiação, expressa em coeficiente de dispersão ou em unidades como a UNT - Unidade Nefelométrica de Turbidez mais freqüentemente usada. Segundo a Resolução CONAMA $\mathrm{n}^{\circ} .20$ de 1986, que classifica as águas interiores no Brasil, na Classe 1 é permitida turbidez até 40,0 NTU, 100,0 NTU para Classes 2 e 3 e acima de 100,0 NTU as águas são classificadas na Classe 4.

Verificou-se que, geralmente, ocorreu elevação da turbidez da água nos pontos posteriores aos lançamentos de águas residuárias nos córregos e que o processo de tratamento do Frigorífico reduz sensivelmente a turbidez do efluente.

Tabela 3. Turbidez em amostras de água nas nove estações de colheita nos Córregos do Marimbondinho e do Tamboril, efluentes do Frigorífico e Ribeirão Marimbondo de agosto de 1998 a julho de 1999; Jales-SP.

\begin{tabular}{|c|c|c|c|c|c|c|c|c|c|}
\hline \multirow{2}{*}{$\begin{array}{l}\text { Data da } \\
\text { colheita }\end{array}$} & \multicolumn{9}{|c|}{ Estações de colheita } \\
\hline & E1 & E2 & E3 & E4 & E5 & E6 & E7 & E8 & E9 \\
\hline $25 / 08 / 98$ & 7,0 & 60,0 & & 71,0 & 105,0 & 125,0 & 10,0 & 120,0 & 15,0 \\
\hline
\end{tabular}




\begin{tabular}{|c|c|c|c|c|c|c|c|c|c|}
\hline 22/09/98 & 4,2 & 20,0 & & & 15,0 & 85,0 & 12,0 & 70,0 & 9,0 \\
\hline 27/10/98 & 150,0 & | 96,0 & & 40,0 & 110,0 & 120,0 & 116,0 & 112,0 & $\mid 100,0$ \\
\hline $0 / 11$ & 50,0 & |68,0 & & & 70,0 & 120,0 & 23,0 & $\mid 120,0$ & 33,0 \\
\hline $6 / 12 / 08$ & 23,0 & $\mid 41,0$ & & & 44,0 & 108,0 & 9,7 & 160,0 & $0 \cap 0$ \\
\hline $19 / 01$ & 46,0 & $\mid 45,0$ & $\mid 180,0$ & 63,0 & 42,0 & 38,0 & 45,0 & 60,0 & 30,0 \\
\hline $25 / 02 / 99$ & 5,4 & $\mid 47,0$ & & & 35,0 & 146,0 & 35,0 & 96,0 & $\mid 149,0$ \\
\hline $10 / 02 / 00$ & 4,5 & 9,5 & & & 9,7 & 110,0 & 6,0 & 98,0 & 050 \\
\hline $26 / 04$ & 6,0 & 8,0 & 200,0 & 110,0 & 7,0 & 120,0 & 8,0 & 180,0 & 90 , \\
\hline 24/05/99 & 4,4 & 7,2 & & & 8,0 & 95,0 & 10,8 & 600,0 & $\mid$\begin{tabular}{||l}
$\mid 460,0$ \\
|
\end{tabular} \\
\hline 21/06/99 & 22,0 & | 27,0 & & & 27,0 & 850,0 & 15,0 & 350,0 & 220,0 \\
\hline 9/07/99 & 4,5 & 8,6 & $\mid 180,0$ & 55,0 & 37,0 & 120,0 & 8,0 & 140,0 & 98, \\
\hline
\end{tabular}

Os pequenos cursos de águas superficiais em áreas desabitadas geralmente apresentam contaminação bacteriana baixa com cerca de 10 a 20 bactérias $/ \mathrm{mL}$; em rios não poluídos este número pode variar entre 100 e 500 bactérias $/ \mathrm{mL}$, ou um pouco mais Em rios poluídos o número dependerá do grau de intensidade da poluição que poderá ser proveniente de esgotos ou do solo.(CETESB, 1991).

Tabela 4. Número Mais Provável (NMP/100mL) de Coliformes Totais em amostras de água nas nove estações de colheita nos Córregos do Marimbondinho e do Tamboril, efluentes do Frigorífico e Ribeirão Marimbondo de agosto de 1998 a julho de 1999; Jales-SP.

\begin{tabular}{|c|c|c|c|c|c|c|c|c|c|}
\hline \multirow{2}{*}{$\begin{array}{l}\text { Data } \\
\text { da } \\
\text { colheita }\end{array}$} & \multicolumn{9}{|c|}{ Estações de colheita } \\
\hline & E1 & E2 & E3 & E4 & E5 & E6 & E7 & E8 & E9 \\
\hline $25 / 08 / 98$ & $4,9 \times 10^{4}$ & $\begin{array}{r}6,3 \\
\times 10^{5}\end{array}$ & & $\mathrm{Nd}$ & $\begin{array}{c}1,1 \\
\times 10^{6}\end{array}$ & $\begin{array}{r}7,2 \\
\times 10^{8}\end{array}$ & $\begin{array}{r}2,9 \\
\times 10^{5}\end{array}$ & $\begin{array}{r}6,2 \\
\times 10^{7}\end{array}$ & $\begin{array}{r}6,2 \\
\times 10^{7}\end{array}$ \\
\hline 22/09/98 & $1,8 \times 10^{4}$ & $\begin{array}{r}1,0 \\
\times 10^{5}\end{array}$ & & & $\begin{array}{r}3,7 \\
\times 10^{6}\end{array}$ & $\begin{array}{r}2,9 \\
\times 10^{8}\end{array}$ & $\begin{array}{r}6,9 \\
\times 10^{4}\end{array}$ & $\begin{array}{r}2,9 \\
\times 10^{7}\end{array}$ & $\begin{array}{r}2,9 \\
\times 10^{7}\end{array}$ \\
\hline 27/10/98 & $\mathrm{Nd}$ & $\mathrm{Nd}$ & $\mathrm{Nd}$ & $\mathrm{Nd}$ & $\mathrm{Nd}$ & $\mathrm{Nd}$ & $\mathrm{Nd}$ & $\mathrm{Nd}$ & $\mathrm{Nd}$ \\
\hline $30 / 11 / 98$ & $3,8 \times 10^{4}$ & $\begin{array}{r}6,3 \\
\times 10^{5}\end{array}$ & & & $\begin{array}{r}6,0 \\
\times 10^{5}\end{array}$ & $\begin{array}{r}2,9 \\
\times 10^{9}\end{array}$ & $\begin{array}{r}1,7 \\
\times 10^{5}\end{array}$ & $\begin{array}{r}6,2 \\
\times 10^{9}\end{array}$ & $\begin{array}{r}6,2 \\
\times 10^{9}\end{array}$ \\
\hline
\end{tabular}




\begin{tabular}{|c|c|c|c|c|c|c|c|c|c|}
\hline $16 / 12 / 98$ & $2,8 \times 10^{3}$ & $\begin{array}{r}3,9 \\
\times 10^{5}\end{array}$ & & & $\begin{array}{c}2,0 \\
\times 10^{5}\end{array}$ & $\begin{array}{c}1,0 \\
\times 10^{8}\end{array}$ & $\begin{array}{r}5,0 \\
\times 10^{4}\end{array}$ & $\begin{array}{r}9,0 \\
\times 10^{7}\end{array}$ & $\begin{array}{r}9,0 \\
\times 10^{7}\end{array}$ \\
\hline 19/01/99 & $1,2 \times 10^{5}$ & $\begin{array}{r}1,1 \\
\times 10^{5}\end{array}$ & $6,5 \times 10^{8}$ & $1,7 \times 10^{4}$ & $\begin{array}{r}1,5 \\
\times 10^{5}\end{array}$ & $\begin{array}{c}1,2 \\
\times 10^{8}\end{array}$ & $\begin{array}{r}1,0 \\
\times 10^{5}\end{array}$ & $\begin{array}{r}3,2 \\
\times 10^{7}\end{array}$ & $\begin{array}{r}3,2 \\
\times 10^{7}\end{array}$ \\
\hline 25/02/99 & $2,3 \times 10^{4}$ & $\begin{array}{r}3,1 \\
\times 10^{6}\end{array}$ & & & $\begin{array}{c}3,4 \\
\times 10^{6}\end{array}$ & $\begin{array}{r}1,7 \\
\times 10^{9}\end{array}$ & $\begin{array}{r}5,2 \\
\times 10^{4}\end{array}$ & $\begin{array}{r}5,2 \\
\times 10^{7}\end{array}$ & $\begin{array}{r}5,2 \\
\times 10^{7}\end{array}$ \\
\hline 18/03/99 & $3,5 \times 10^{2}$ & $\begin{array}{r}9,8 \\
\times 10^{3}\end{array}$ & & & $\begin{array}{r}5,3 \\
\times 10^{4}\end{array}$ & $\begin{array}{r}3,6 \\
\times 10^{6}\end{array}$ & $\begin{array}{r}4,1 \\
\times 10^{4}\end{array}$ & $\begin{array}{r}4,8 \\
\times 10^{6}\end{array}$ & $\begin{array}{r}4,8 \\
\times 10^{6}\end{array}$ \\
\hline 26/04/99 & $3,6 \times 10^{4}$ & $\begin{array}{c}1,7 \\
\times 10^{4}\end{array}$ & $1,6 \times 10^{8}$ & $\begin{array}{c}7,4 \\
\times 10^{5}\end{array}$ & $\begin{array}{r}3,7 \\
\times 10^{4}\end{array}$ & $\begin{array}{r}3,1 \\
\times 10^{7}\end{array}$ & $\begin{array}{r}1,3 \\
\times 10^{5}\end{array}$ & $\begin{array}{r}4,7 \\
\times 10^{7}\end{array}$ & $\begin{array}{r}4,7 \\
\times 10^{7}\end{array}$ \\
\hline $24 / 05 / 99$ & $2,7 \times 10^{4}$ & $\begin{array}{c}1,5 \\
\times 10^{5}\end{array}$ & & & $\begin{array}{c}5,2 \\
\times 10^{4}\end{array}$ & $\begin{array}{r}3,1 \\
\times 10^{7}\end{array}$ & $\begin{array}{r}7,0 \\
\times 10^{4}\end{array}$ & $\begin{array}{r}6,8 \\
\times 10^{7}\end{array}$ & $\begin{array}{r}6,8 \\
\times 10^{7}\end{array}$ \\
\hline $21 / 06 / 99$ & $1,6 \times 10^{5}$ & $\begin{array}{c}3,9 \\
\times 10^{5}\end{array}$ & & & $\begin{array}{r}1,1 \\
\times 10^{6}\end{array}$ & $\begin{array}{r}1,6 \\
\times 10^{8}\end{array}$ & $\begin{array}{r}7,9 \\
\times 10^{5}\end{array}$ & $\begin{array}{r}5,4 \\
\times 10^{7}\end{array}$ & $\begin{array}{r}5,4 \\
\times 10^{7}\end{array}$ \\
\hline 29/07/99 & $1,8 \times 10^{4}$ & $\begin{array}{c}6,1 \\
\times 10^{4}\end{array}$ & $2,2 \times 10^{8}$ & $\begin{array}{c}1,0 \\
\times 10^{5}\end{array}$ & $\begin{array}{r}7,6 \\
\times 10^{4}\end{array}$ & $\begin{array}{r}1,6 \\
\times 10^{7}\end{array}$ & $\begin{array}{r}3,9 \\
\times 10^{4}\end{array}$ & $\begin{array}{r}5,7 \\
\times 10^{7}\end{array}$ & $\begin{array}{r}5,7 \\
\times 10^{7}\end{array}$ \\
\hline
\end{tabular}

Nd - Não detectado

A presença de bactérias coliformes na água é uma indicação de riscos potenciais à saúde devido à sua associação com patógenos intestinais (PEÇANHA, 1993).

Os esgotos domésticos contribuem com números consideráveis de bactérias. Ao se tomar água de um rio no ponto em que recebe esgotos domésticos, a contaminação bacteriana é elevada e tende a reduzir à medida que flui devido ao fenômeno de autodepuração (PIVELI, R. P.; MORITA, D. M., 1996)

Tabela 5. Número Mais Provável (NMP/100mL) de Escherichia coli em amostras de água nas nove estações de colheita nos Córregos do Marimbondinho e do Tamboril, efluentes do Frigorífico e Ribeirão Marimbondo; agosto de 1998 a julho de 1999. JalesSP.

\begin{tabular}{|c|c|c|c|c|c|c|c|c|c|}
\hline \multirow{2}{*}{$\begin{array}{l}\text { Data da } \\
\text { Colheita }\end{array}$} & \multicolumn{9}{|c|}{ Estações de colheita } \\
\hline & E1 & $\mathrm{E} 2$ & E3 & E4 & E5 & E6 & E7 & E8 & E9 \\
\hline $25 / 08 / 98$ & $1,0 \times 10^{3}$ & $\begin{array}{c}1,0 \\
\times 10^{5}\end{array}$ & & $\mathrm{Nd}$ & $\begin{array}{c}3,0 \\
\times 10^{4}\end{array}$ & $\begin{array}{l}9,5 \\
\times 10^{7}\end{array}$ & $\begin{array}{l}9,3 \\
\times 10^{4}\end{array}$ & $\begin{array}{c}2,4 \\
\times 10^{7}\end{array}$ & $\begin{array}{r}7,9 \\
\times 10^{5}\end{array}$ \\
\hline
\end{tabular}




\begin{tabular}{|c|c|c|c|c|c|c|c|c|c|}
\hline $22 / 09 / 98$ & $9,8 \times 10^{2}$ & $\begin{array}{c}3,4 \\
\times 10^{4}\end{array}$ & & & $\begin{array}{c}2,4 \\
\times 10^{6}\end{array}$ & $\begin{array}{c}6,4 \\
\times 10^{7}\end{array}$ & $\begin{array}{c}8,6 \\
\times 10^{3}\end{array}$ & $\begin{array}{c}7,2 \\
\times 10^{6}\end{array}$ & $\begin{array}{c}2,4 \\
\times 10^{6}\end{array}$ \\
\hline $27 / 10 / 98$ & $\mathrm{Nd}$ & $\mathrm{Nd}$ & $\mathrm{Nd}$ & $\mathrm{Nd}$ & $\mathrm{Nd}$ & $\mathrm{Nd}$ & $\mathrm{Nd}$ & $\mathrm{Nd}$ & $\mathrm{Nd}$ \\
\hline $30 / 11 / 98$ & $2,0 \times 10^{3}$ & $\begin{array}{c}1,0 \\
\times 10^{5}\end{array}$ & & & $\begin{array}{r}2,5 \\
\times 10^{5}\end{array}$ & $\begin{array}{r}1,2 \\
\times 10^{9}\end{array}$ & $\begin{array}{c}6,3 \\
\times 10^{4}\end{array}$ & $\begin{array}{c}2,4 \\
\times 10^{9}\end{array}$ & $\begin{array}{c}2,4 \\
\times 10^{7}\end{array}$ \\
\hline $16 / 12 / 98$ & $3,1 \times 10^{2}$ & $\begin{array}{c}1,0 \\
\times 10^{4}\end{array}$ & & & $\begin{array}{c}1,0 \\
\times 10^{5}\end{array}$ & $\begin{array}{c}1,0 \\
\times 10^{8}\end{array}$ & $\begin{array}{c}2,0 \\
\times 10^{4}\end{array}$ & $\begin{array}{c}1,0 \\
\times 10^{7}\end{array}$ & $\begin{array}{c}2,9 \\
\times 10^{6}\end{array}$ \\
\hline $19 / 01 / 99$ & $8,5 \times 10^{3}$ & $\begin{array}{r}4,1 \\
\times 10^{3}\end{array}$ & $\begin{array}{c}5,7 \\
\times 10^{8}\end{array}$ & $\begin{array}{c}3,1 \\
\times 10^{3}\end{array}$ & $\begin{array}{c}3,0 \\
\times 10^{4}\end{array}$ & $\begin{array}{r}6,2 \\
\times 10^{7}\end{array}$ & $\begin{array}{r}6,2 \\
\times 10^{3}\end{array}$ & $\begin{array}{c}9,3 \\
\times 10^{6}\end{array}$ & $\begin{array}{r}1,5 \\
\times 10^{7}\end{array}$ \\
\hline $25 / 02 / 99$ & $9,8 \times 10^{2}$ & $\begin{array}{c}7,4 \\
\times 10^{3}\end{array}$ & & & $\begin{array}{c}8,8 \\
\times 10^{5}\end{array}$ & $\begin{array}{r}1,2 \\
\times 10^{7}\end{array}$ & $\begin{array}{c}1,6 \\
\times 10^{3}\end{array}$ & $\begin{array}{c}1,3 \\
\times 10^{7}\end{array}$ & $\begin{array}{r}4,8 \\
\times 10^{5}\end{array}$ \\
\hline $18 / 03 / 99$ & $3,1 \times 10^{1}$ & $\mathrm{Nd}$ & & & $\begin{array}{c}1,6 \\
\times 10^{4}\end{array}$ & $\begin{array}{c}1,0 \\
\times 10^{6}\end{array}$ & $\begin{array}{c}7,3 \\
\times 10^{3}\end{array}$ & $\begin{array}{c}1,2 \\
\times 10^{6}\end{array}$ & $\begin{array}{c}3,4 \\
\times 10^{5}\end{array}$ \\
\hline 26/04/99 & $1,0 \times 10^{3}$ & $\begin{array}{c}1,0 \\
\times 10^{3}\end{array}$ & $\begin{array}{c}4,6 \\
\times 10^{7}\end{array}$ & $<1$ & $\begin{array}{r}4,1 \\
\times 10^{3}\end{array}$ & $\begin{array}{r}1,5 \\
\times 10^{7}\end{array}$ & $\begin{array}{c}2,5 \\
\times 10^{4}\end{array}$ & $\begin{array}{c}1,3 \\
\times 10^{7}\end{array}$ & $\begin{array}{c}1,3 \\
\times 10^{6}\end{array}$ \\
\hline $24 / 05 / 99$ & $1,3 \times 10^{3}$ & $\begin{array}{r}8,5 \\
\times 10^{3}\end{array}$ & & $\begin{array}{c}5,1 \\
\times 10^{4}\end{array}$ & $\begin{array}{c}1,0 \\
\times 10^{4}\end{array}$ & $\begin{array}{c}1,4 \\
\times 10^{7}\end{array}$ & $\begin{array}{c}3,4 \\
\times 10^{4}\end{array}$ & $\begin{array}{c}3,7 \\
\times 10^{7}\end{array}$ & $\begin{array}{c}3,1 \\
\times 10^{6}\end{array}$ \\
\hline $21 / 06 / 99$ & $1,3 \times 10^{4}$ & $\begin{array}{c}2,5 \\
\times 10^{4}\end{array}$ & & & $\begin{array}{c}4,1 \\
\times 10^{4}\end{array}$ & $\begin{array}{r}6,5 \\
\times 10^{7}\end{array}$ & $\begin{array}{r}3,7 \\
\times 10^{5}\end{array}$ & $\begin{array}{c}2,2 \\
\times 10^{7}\end{array}$ & $\begin{array}{c}1,7 \\
\times 10^{6}\end{array}$ \\
\hline 29/07/99 & $3,1 \times 10^{3}$ & $\begin{array}{c}9,8 \\
\times 10^{3}\end{array}$ & $\begin{array}{c}5,0 \\
\times 10^{7}\end{array}$ & & $\begin{array}{c}2,0 \\
\times 10^{4}\end{array}$ & $\begin{array}{c}1,3 \\
\times 10^{6}\end{array}$ & $<1$ & $\begin{array}{c}1,3 \\
\times 10^{7}\end{array}$ & $\begin{array}{c}2,1 \\
\times 10^{6}\end{array}$ \\
\hline
\end{tabular}

Nd - Não detectado

Verificou-se que as cargas de poluentes contribuem para as elevadas concentrações de bactérias coliformes totais e Escherichia coli que aumentam sensivelmente nas amostras de água colhidas nas estações posteriores aos emissários de esgotos domésticos e efluentes do Frigorífico, quando comparadas com as estações de anteriores aos lançamentos, localizadas nos Córregos do Marimbondinho e Tamboril (Tabelas 4 e 5).

BORGES, 2001, avaliou parâmetros de qualidade da água em córregos do Município de Jaboticabal - SP e encontrou alterações nos níveis de DQO, DBO, Coliformes Totais e E. coli, entre outros, como conseqüência da poluição provocada por águas residuárias, semelhante ao encontrado nesta pesquisa. 
- A comparação entre as análises realizadas nas estações anteriores e posteriores aos emissários mostra que os esgotos domésticos da cidade de Jales, não tratados, contribuem intensamente para a poluição das águas dos Córregos do Marimbondinho e Tamboril e Ribeirão Marimbondo. Entretanto, observa-se que a água não apresenta qualidade mesmo antes de receber os esgotos.

- As cargas de poluentes contribuem para as elevadas concentrações de bactérias coliformes totais e Escherichia coli que aumentam sensivelmente nas amostras de água coletadas nas estações posteriores aos emissários de esgotos domésticos e efluentes do Frigorífico, quando comparadas com as estações de colheitas anteriores aos lançamentos, localizadas nos Córregos do Marimbondinho e Tamboril. A água destes córregos e do Ribeirão Marimbondo, segundo a Resolução n. ${ }^{\circ}$ 20, de 1986, do CONAMA (BRASIL, 1986), é imprópria quanto a balneabilidade, nas estações E1, E2, E5, E6, E7, E8 e E9, por apresentarem coliformes totais acima de $5.000 / 100 \mathrm{~mL}$ e coliformes fecais acima de $1.000 / 100 \mathrm{~mL}$.

- Os Córregos do Marimbondinho e Tamboril levam a carga de poluentes que recebem para o Ribeirão Marimbondo, contribuindo para o aumento da poluição e degradação da qualidade da água na Bacia Hidrográfica do Rio São José dos Dourados. Em relação aos seus usos preponderantes, segundo a Resolução do CONAMA, as estações E1, E2, E5, E6, E7, E8 e E9 são classificadas como Classe 4, isto é, estas águas podem destinar-se à navegação comercial, à harmonia paisagística e aos usos menos exigentes.

- O tratamento de resíduos líquidos do Frigorífico reduz a carga de poluentes no efluente, embora ainda contribua bastante para a elevação dos níveis de poluição do Córrego do Marimbondinho e Ribeirão Marimbondo. Baseado na Resolução CONAMA, nos parâmetros turbidez, DBO e coliformes, a estação (E4) Efluente do Frigorífico, mesmo após tratamento do esgoto, não poderia ser lançado no Córrego do Marimbondinho.

- Faz-se necessária a construção, no menor espaço de tempo possível, da estação de tratamento de esgotos domésticos de Jales, bem como, bem como melhor eficiência do tratamento do efluente do Frigorífico, para reduzir o despejo de poluentes nos córregos do Marimbondinho e do Tamboril.

\section{REFERÊNCIAS}

APHA (AMERICAN PUBLIC HEALTH ASSOCIATION). Standard methods for the examination of water and wastewater. 19.ed. Washington, 1995.

AZPURUA, P. P., GABALDON, A. Recursos hidráulicos y desarrollo. Madrid: Editorial Tecnos, 1976. 
BARCELOS, V. H. DE L. A temática ambiental e a formação de professores: uma contribuição aos cursos de licenciatura da UFSM. Santa Maria, RS. Biblioteca Setorial "Carmen Silveira Netto", Maio/1997, 40p. (Cadernos Didáticos de Ensino, Pesquisa e Extensão, 04).

BORGES, M. J. Avaliação de parâmetros de qualidade de solo e da água em áreas dos Córregos Cerradinho e Jaboticabal, como subsídio para o planejamento ambiental. 2001. 114f. Dissertação (Mestrado em Conservação e Manejo de Recursos) - Centro de Estudos Ambientais, Universidade Estadual Paulista, Rio Claro, 2001.

BRASIL. Resolução CONAMA n. 20, 18 junho 1986. Estabelece classificação das águas doces, salobras e salinas do território nacional. Diário Oficial, Brasília, p.11.356, 1986.

Companhia de Saneamento Básico do Estado de São Paulo - SABESP. dqo. .São Paulo, SABESP, 1997. 8p. (Norma técnica NTS - 04/97).

COMPANHIA DE TECNOLOGIA DE SANEAMENTO AMBIENTAL - CETESB. Determinação da turbidez em águas. Método nefelométrico. São Paulo, CETESB, 1987. 7 p. (Normalização técnica L5. 156).

COMPANHIA DE TECNOLOGIA DE SANEAMENTO AMBIENTAL - CETESB. Interpretação de laudos físico-químicos, hidrobiológicos e bacteriológicos em sistemas de abastecimento público de água. São Paulo, CETESB, 1991. 130p.

INSTITUTO BRASILEIRO DE GEOGRAFIA E ESTATÍSTICA (1996). Resultados relativos a sexo da população e situação da unidade domiciliar. Rio de Janeiro: Ministério do Planejamento e Orçamento/IBGE, 1997. v.1. (Contagem da População - 1996).

MACEDO, R.K. "A importância da avaliação ambiental". In: TAUK, S.M. (Org.) Análise ambiental: uma visão multidisciplinar. São Paulo: UNESP/FAPESP, 1991. p.11-26.

MOITA, R.; CUDO, K. J. Aspectos gerais da qualidade da água no Brasil. In: REUNIÃ̃O TÉCNICA SOBRE QUALIDADE DA ÁGUA PARA CONSUMO HUMANO E SAÚDE NO BRASIL. 1991, Brasília. P. 1-6.

MOURA, M. Taxação de uso da água provoca polêmica. O Estado de São Paulo, São Paulo, 21 dez. 1997. Geral, p.18.

PALMA-SILVA, g. m. Diagnóstico ambiental, qualidade da água e índice de depuração do Rio Corumbataí-SP. 1999. 155f. Dissertação (Mestrado em Manejo 
Integrado de Recursos) - Centro de Estudos Ambientais, Universidade Estadual Paulista, Rio Claro, 1999.

PEÇANHA, M. P. Parâmetros microbiológicos da água do Ribeirão Claro (Rio Claro-São Paulo). 1993. 129 f. Dissertação (Mestrado em Biologia Vegetal) Instituto de Biociências, Universidade Estadual Paulista, Rio Claro.

PHILIPPI JÚNIOR, A. (Org.) Saneamento do meio. São Paulo: FUNDACENTRO/USP. 1992. 235p.

PIVELI, R. P.; MORITA, D. M. Caracterização de águas residuárias: oxigênio dissolvido e medidas de matéria orgânica. 1996. 54p.

PREFEITURA MUNICIPAL DE JALES. Departamento de Viação e Obras Públicas. Mapa do Município de Jales. Jales: DVOP, 1980. Mapa p\&b, 92x75cm. Escala: 1: 50.000 .

REBOUÇAS, A. C. Falta uma política nacional de águas. Ciência Hoje, v.19. n. 110. p.52-9, 1995. 